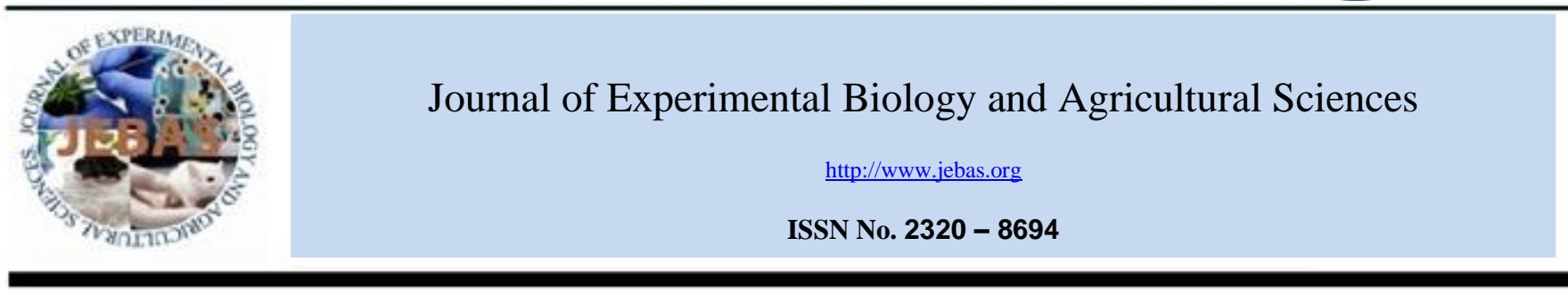

\title{
ASSOCIATION OF TELOMERASE ACTIVITY WITH THE PROGNOSIS OF DIABETES MELLITUS IN SAUDI POPULATION
}

\author{
Taha A. Kumosani ${ }^{1,2}$, Archana P. Iyer ${ }^{1,2, *}$, Ayat B. Al-Ghafari ${ }^{1,2}$, Mazin A. Zamzami ${ }^{1}$ \\ ${ }^{1}$ Department of Biochemistry, King Abdulaziz University, Jeddah, Saudi Arabia \\ ${ }^{2}$ Experimental Biochemistry Unit, King Fahad Medical Research Centre, King Abdulaziz University, Jeddah, Saudi Arabia
}

Received - May 09, 2017; Revision - June 17, 2017; Accepted - June 29, 2017

Available Online - June 30, 2017

DOI: http://dx.doi.org/10.18006/2017.5(3).277.281

\section{KEYWORDS}

Type 2 diabetes

PCR-ELISA

Telomerase activity

Type I diabetes

Gestational diabetes

\footnotetext{
* Corresponding author

E-mail: arch729@gmail.com (Archana P. Iyer)
}

Peer review under responsibility of Journal of Experimental Biology and Agricultural Sciences.

Production and Hosting by Horizon Publisher India [HPI] (http://www.horizonpublisherindia.in/).

All rights reserved.

\begin{abstract}
Telomeres are important for chromosome stability and they are replenished by telomerase enzyme. Impaired telomerase activity has a strong association with ageing and diabetes. Research data have shown that telomerase activity plays a vital role in pathogenesis of type I and type II diabetes by influencing pancreatic cell regeneration. This study was aimed to assess telomerase activity in three diabetic groups (type I, type II and gestational diabetes mellitus (GDM)) and compare it with a population with normal blood glucose levels to establish a correlation between reduced telomerase activity and prognosis of diabetes in the Saudi population. This study was conducted on 200 Saudi diabetic and non-diabetic participants (20-60 years). Peripheral mononuclear cells (PMNCs) were extracted from the blood samples and the activity of telomerase in the PMNCs was detected by the TRAP-ELISA assay. Results of study revealed that there was no telomerase activity in control healthy group, moderate activity in type I, some activity in GDM, and significantly high activity in type II group. This might indicate that telomerase activity has a strong correlation to the prognosis of type II diabetes. However, the molecular mechanism still needs to be investigated.
\end{abstract}

All the article published by Journal of Experimental Biology and Agricultural Sciences is licensed under a Creative Commons Attribution-NonCommercial 4.0 International License Based on a work at www.jebas.org.






\section{Introduction}

At each end of eukaryotic chromosomes, there are regions of repetitive nucleotide sequences known as telomeres. These regions protect the chromosomes from being fused with neighboring chromosomes. The average telomere length in human chromosomes ranges from $11 \mathrm{~kb}$ to less than $4 \mathrm{~kb}$ from birth to older ages, respectively (Arai et al., 2015). Each time the cell is divided, the length of telomere decrease (Shay, 2016). However, these shortened ends are replenished by specific enzyme known as telomerase (Greider \& Blackburn, 1985; Greider \& Blackburn, 1989; Parks \& Stone, 2017). Telomerase is a ribonucleoprotein enzyme that composed of reverse transcriptase enzyme and a long non-coding RNA required for telomere synthesis (Blackburn, 1991). The high expression of telomerase is most notably in germline cells and many cancerous cells (Shay, 2016; Armstrong \& Tomita, 2017). Telomerase is a marker for several physiological processes such as cellular proliferation activity, ageing process (senescence), and cell-death (apoptosis). Moreover, it helps in the diagnosis of human tumors and regeneration of damaged tissue particularly liver and heart (Salpea \& Humphries, 2010).

In recent years, several studies have been conducted to correlate telomeres shortening and telomerase activity with several metabolic diseases notably cardiovascular diseases, cancer and diabetes (Adaikalakoteswari et al., 2007; Salpea \& Humphries, 2010; Elks \& Scott, 2014). Diabetes mellitus (DM) considered one of the prevalent metabolic disorders. According to the latest World Health Organization (WHO) report, the rate of diabetes in Saudi Arabia is high (it ranks the second highest rate in the Middle East, and the seventh worldwide) (Al Dawish et al., 2016). Studies have shown that diabetic patients are apparently having shorter telomeres in their chromosomes (Tamura et al., 2016). It is not clear if the shortened telomeres have a role in diabetes pathogenesis (Adaikalakoteswari et al., 2007). However, it is well-known that telomeres are important in the progression and complications of diabetes including nephropathy (Verzola et al., 2008) and microalbuminuria (Tntolouris et al., 2007). Therefore, more investigations are needed to determine the relation of telomeres shortening and telomerase activity with diabetes pathogenesis.

The detection of the telomerase activity in tissues under normal physiological or pathological conditions is important step for tissue homeostasis. Several techniques are available to detect telomerase activity such as telomeric repeat amplification protocol (TRAP) assay, the fluorescent TRAP (F-TRAP) assay, stretch PCR assay, and transcription mediated amplification with the hybridization protection (TMA-HPA) assay (Durusoy \& Üztürk, 2001). These assays can either directly measure telomerase products, or indirectly measure the amplification signals produced from DNA that yields from telomerase (Wei et al., 1997; Skvortsov et al., 2011). Telomeric repeat amplification protocol (TRAP) is one of the oldest techniques used to measure the activity of telomerase. This technique has number of limitations that lead to the development of other modified techniques such as TRAP-ELISA. TRAP-ELISA assay is a non-radioisotopic technique that combines PCRELISA with TRAP to determine the telomerase activity, quantitatively and qualitatively, in a wide range of human tissues (Wei et al., 1997). Therefore, the current study was performed to estimate the telomerase activity in three types of diabetes mellitus namely type I diabetes mellitus (T1DM), type II diabetes mellitus (T2DM) and gestational diabetes mellitus (GDM). People diagnosed clinically with this disease were assessed for telomerase activity by the TRAP-ELISA assay. Then the telomerase activity was compared to a group of control subjects with normal blood glucose levels to investigate the role of telomerase activity in the maintenance of normal blood glucose levels and impaired glucose metabolism in the Saudi population.

\section{Materials and Methods}

\subsection{Study Subjects and Samples}

This study was conducted on 200 Saudi males and females (2060 years), Who routinely attended the diabetes clinic, Association of Diabetic Patient Friends Jeddah, King Abdulaziz University Hospital (KAUH), Jeddah, Saudi Arabia. The unit of Biochemical Ethics Research committee (UBERC) at King Abdulaziz University approved this study. All subjects gave their written consent for their participation in the study and based on their blood glucose levels, they were classified into four groups namely: normal glucose metabolism, T1DM, T2DM and GDM. The control group consisted of 25 males and 25 females, their mean ages ranged from 37 to 60 years and they had overnight fasting blood glucose levels of $<110 \mathrm{mg} / \mathrm{dl}$. The T1DM and T2DM subjects, were $(20$ males and 30 females) and ( 25 males and 25 females) in the same age group between 37 to 60 years who had a fasting blood glucose of $>110 \mathrm{mg} / \mathrm{dl}$. Regarding the GDM group, samples were collected from 50 pregnant females who only showed elevated blood glucose levels.

\subsection{Separation of Peripheral Blood Mononuclear Cells (PBMCs)}

From each participant, $5 \mathrm{ml}$ of peripheral blood were collected in tubes contain heparin anticoagulant. Then $2.5 \mathrm{ml}$ of Ficoll was added to each sample and was centrifuged at $2000 \mathrm{rpm}$ for $20 \mathrm{~min}$. After centrifugation, the PBMCs were collected from the Ficoll/plasma interface and they were washed three times in normal saline before they were pelleted by low-speed centrifugation. Finally, the cells $\left(2 \times 10^{5} /\right.$ tube) were collected and stored at $-80 \mathrm{C}$ for telomerase assay (Yao et al., 2006).

\subsection{TRAP Reaction}

The telomerase activity in PBMCs was determined by a commercial telomerase TRAP-ELISA kit (TRAPEZE® ELISA Telomerase Detection Kit, Chemicon International, cat. No. S7750) by following manufacturer's instructions. To perform TRAP reaction, $2 \times 10^{5}$ PBMCs were lysed in $200 \mu \mathrm{l}$ lysis reagent and incubated for $30 \mathrm{~min}$. Following the incubation 
period, cells were centrifuged at $16000 \mathrm{rpm}$ for $20 \mathrm{~min}$ at $4^{\circ} \mathrm{C}$ and the supernatant was removed and was kept frozen at -80 ${ }^{\circ} \mathrm{C}$. The telomeric repeats were added to a primer (biotinlabeled) for $30 \mathrm{~min}$ at $25^{\circ} \mathrm{C}$ during the first reaction. To induce telomerase inactivation, the mixture was incubated at $94^{\circ} \mathrm{C}$ for 5 min, then was subjected to $30 \mathrm{PCR}$ cycles as follow: $94^{\circ} \mathrm{C}$ for $30 \mathrm{~s}, 50^{\circ} \mathrm{C}$ for $30 \mathrm{~s}$, and $72^{\circ} \mathrm{C}$ for $90 \mathrm{~s}$, and final extension at $72^{\circ} \mathrm{C}$ for $10 \mathrm{~min}$. These PCR products were used for the analysis of telomerase activity and gel electrophoresis alongside two types of controls [the positive control was (immortalized telomerase-expressing human kidney cells) and the negative control cell extract was (heat-treatment of the cell extract for $10 \mathrm{~min}$ at $65^{\circ} \mathrm{C}$ prior to the TRAP reaction)] (Yao et al., 2006).

\subsection{Detection of Telomerase Activity}

The denatured PCR product was hybridized to a digoxigenin(DIG)-labeled, telomeric repeat-specific detection probe. Then, via biotin labeled primer, the resulted product was immobilized to a streptavidin coated microtiter plate. The detection was performed using a peroxidase- conjugated antibody against digoxigenin (anti-DIG-POD). Within 30 min of adding the stop reagent, the probe was visualized with peroxidase metabolizing tetramethyl benzidine (TMB) and the absorbance (A) was measured at $450 \mathrm{~nm}$. Telomerase activities were expressed using the following equation $=$ Absorbance of sample Absorbance of negative control (Yao et al., 2006).

\subsection{Statistical Analysis}

Comparison of telomerase activity between normal glucose subjects and different categories of diabetes was done using
GraphPad Prism version 7.0 to establish a possible correlation between reduced telomerase activity and the prognosis of diabetes in Saudi population. Results were statistically analyzed using one-way analysis of variance (one-way ANOVA) test and $p$ values were corrected with Bonferroni's correction post hoc test. $P$ values $<0.05$ were considered statistically significant.

\section{Results}

\subsection{Determination of Telomerase Activity}

The absorbance of telomerase activity was calculated and represented as mean \pm SEM. Comparisons of mean revealed that patients with T1DM $(0.253 \pm 0.027)$, T2DM $(0.752 \pm 0.054)$, and GDM $(0.192 \pm 0.036)$ had a significant telomerase activity $(p<0.05)$ compared to control group $(0.038 \pm 0.006)$. However, patients with T2DM $(0.752 \pm 0.054)$ had the highest telomerase activity among the diabetic groups when compared to control group $(* * * p \leq 0.001)$.

\section{Discussions}

Since the discovery of telomerase, several studies have been performed to identify its role and how to measure its activity. Telomerase activity is usually less in most normal somatic cells compared to cancer cells (Kim et al., 1994). Human telomerase activity can be assessed by using several assays such as TRAP assay (Durusoy \& Üztürk, 2001). The deregulation of telomerase expression and activity was found to be linked to several metabolic syndromes and diseases such as diabetes (Cong et al., 2002).

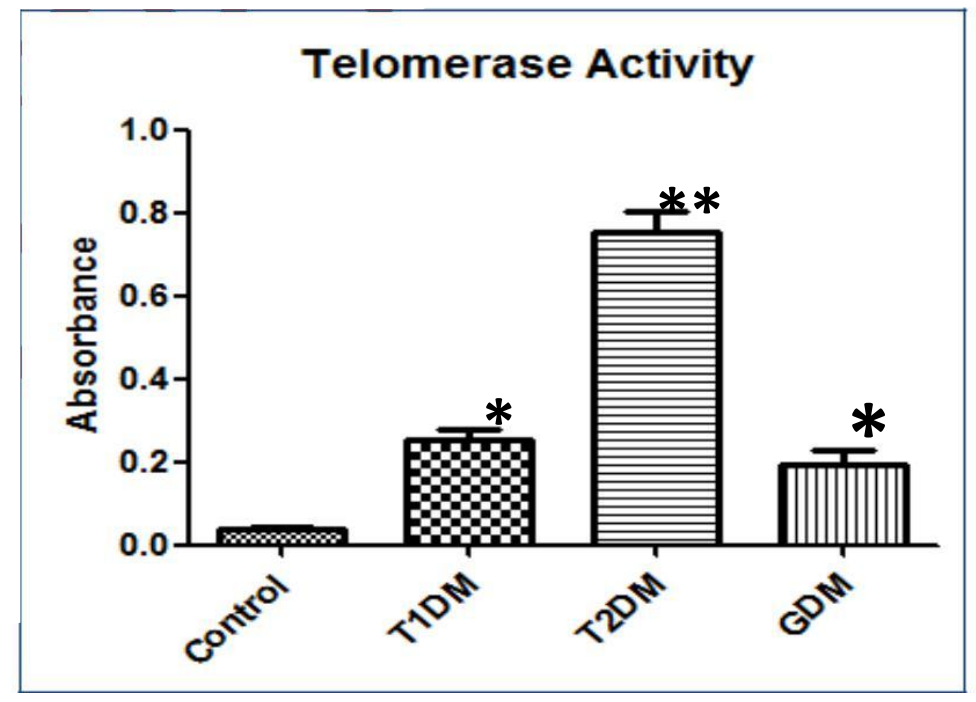

Figure 2 The absorbance of telomerase activity in control subjects versus different diabetic patient groups. The telomerase activity, obtained from TRAP-ELISA assay, was analyzed by one-way ANOVA test followed by Bonferroni's correction. Data were represented as mean $\pm \mathrm{SEM}$ and $\mathrm{P}$ values were obtained by comparing the means of each diabetic group vs. control group ( ${ }^{*} \mathrm{p}<0.05$ and $\left.* * * \mathrm{p} \leq 0.001\right)$. 
In the current study, telomerase activity was evaluated in three different diabetic groups (T1DM, T2DM, and GDM) and compared to control non-diabetic group in order to estimate the possible role of telomerase in the prognosis of diabetes. As shown by the absorbance of telomerase activity with TRAPELISA assay, it was reported that there was no telomerase activity in control healthy group while moderate activity was reported in T1DM, some activity in GDM, and significantly high activity in T2DM group, which might indicate that telomerase activity has a role in the prognosis of T2DM. However, the exact mechanisms behind this strong link need more investigation. One of the postulated mechanisms that could explain the possible correlation is the production of senescence in premature pancreatic $\beta$-cell because of short telomeres, which in turn reduced $\beta$-cell mass and subsequently inhibit insulin secretion and cause glucose intolerance (Arai et al., 2015). Further, Oxidative stress damages telomeres, and diabetics usually have short telomeres and abnormal telomerase activity (Serra et al., 2000). In an in vivo study on mice, telomerase was found to play a role in maintaining glucose homeostasis (Kuhlow et al., 2010). Conversely, high levels of glucose elevate oxidative stress rate, therefore, impaired telomerase function and resulted in shortened telomeres (Serra et al., 2000). Findings of Zhao et al. (2014) are in agreement of the results of present study. These researchers studied the correlation between leukocyte telomeres length with the development of T2DM. They found that shortened telomeres are associated with T2DM development independently on risk factors. Their result apparently confirms that threshold effect is related to telomere length and cellular senescence. Another study performed by Rentoukas et al. (2012) to reveal the effect of telomerase in patients with inflammation and impaired endothelial function found that patients with metabolic syndromes had significant telomerase activity in their circulating PBMC. These results suggested that prolonged inflammation could act as a pathway in atherosclerosis resulted from diabetes.

In contrast to findings of this study, a study was conducted on newly diagnosed T2DM patients to determine the effect of Sitagliptin medicine on telomere length and telomerase activity, found that leukocyte telomere length was significantly reduced although that telomerase activity was less influenced. This result indicated that Sitagliptin might protect pancreatic $\beta$ cells from damage by elongating the length of its telomere (Ma et al., 2014). Moreover, a previous study performed on cord blood samples from pregnant women with pregestational T1DM, T2DM and gestational diabetes found significant differences between groups telomerase activity (it was high in cord blood from Type 1 and gestational diabetes pregnancies, but not in Type 2 diabetes) (Cross et al., 2010).

It is also important to state that telomerase expression and activity have been found to be upregulated not only in diabetes but also in other diseases that are classified as complications of diabetes. In vascular smooth muscle cells of diabetic patients, telomerase enzyme activity was found highly upregulated. This finding is crucial since high proliferation of these cells contributes to atherosclerosis and vascular disease (Sun et al., 2013).

In conclusion, although telomerase activity has been theoretically linked to cell ageing, damage and tumor phenotype, not much work has been published in relation to the possible association of increased telomerase activity with metabolic syndrome. To the best of our knowledge, our study is the first one that compares activity of telomerase in all three types of diabetes and we have found significantly high activity in type II diabetic patients as compared with type I and gestational diabetes. Hence, we recommend using these interesting findings as a starting point to pursue further research in this area with a higher sample size.

\section{Acknowledgement}

This project was funded by the Deanship of Scientific Research (DSR) at King Abdulaziz University, Jeddah, under grant no. (G-564-130-37). The authors, therefore, acknowledge with thanks DSR for technical and financial support.

\section{Conflict of interest}

Authors would hereby like to declare that there is no conflict of interests that could possibly arise.

\section{References}

Adaikalakoteswari A, Balasubramanyam M, Ravikumar R, Deepa R, Mohan V (2007) Association of telomere shortening with impaired glucose tolerance and diabetic macroangiopathy. Atherosclerosis 195:83-89.

DOI:10.1016/j.atherosclerosis.2006.12.003

Al Dawish MA, Robert AA, Braham R (2016) Diabetes mellitus in Saudi Arabia: a review of the recent literature.

Current Diabetes Reviews 12:1-10. DOI: 10.2174/1573399811666150724095130

Arai Y, Martin-Ruiz CM, Takayama M, Abe Y, Takebayashi T, Koyasu S, Suematsu M, Hirose N, von Zglinicki T (2015) Inflammation, but not telomere length, predicts successful aging at extreme old age: a longitudinal study of semi-

supercentenarians. EBioMedicine 2: 1549-48. DOI: http://dx.doi.org/10.1016/j.ebiom.2015.07.029

Armstrong CA, Tomita K (2017) Fundamental mechanisms of telomerase action in yeasts and mammals: understanding telomeres and telomerase in cancer cells. Open Biology 7:160338. DOI: 10.1098/rsob.160338

Blackburn EH (1991) Structure and functions of telomeres. Nature 350: 569-73. DOI: 10.1038/350569a0

Cong YS, Wright WE, Shay JW (2002) Human telomerase and its regulation. Microbiology and Molecular Biology Reviews 66:407-425. DOI: 10.1128/MMBR.66.3.407-425.2002 
Cross JA, Temple RC, Hughes JC, Dozio NC, Brennan C, Stanley K, Murphy HR, Fowle D, Hughes DA, Sampson MJ (2010) Cord blood telomere length, telomerase activity and inflammatory markers in pregnancies in women with diabetes or gestational diabetes. Diabetic Medicine 27: 1264-1270. DOI: 10.1111/j.1464-5491.2010.03099.x

Durusoy M, Üztürk K (2001) Methods used in evaluation telomerase activity. Turkish Journal of Medical Sciences 31:381-384.

Elks CE, Scott RA (2014) The long and short of telomere length and diabetes. Diabetes 63:65-67. DOI: $10.2337 / \mathrm{db} 13-$ 1469

Greider CW, Blackburn EH (1985) Identification of a specific telomere terminal transferase activity in Tetrahymena extracts. Cell 43:405-413. DOI: 0092-8874/85/120405-09

Greider CW, Blackburn EH (1989) A telomeric sequence in the RNA of Tetrahymena telomerase required for telomere repeat synthesis. Nature 337:331-337. DOI:10.1038/337331a0

Kim NW, Piatyszek MA, Prowse KR, Harley MD, West CB, Ho PL, Coviello GM, Wright WE, Weinrich SL, Shay JW (1994) Specific association of human telomerase activity with immortal cells and cancer. Science 266:2011-2015. DOI: $10.1126 /$ science. 7605428

Kuhlow D, Florian S, von Figura G, Weimer S, Schulz N, Petzke KJ, Zarse K, Pfeiffer, AF, Rudolph KL, Ristow M (2010) Telomerase deficiency impairs glucose metabolism and insulin secretion. Aging (Albany, NY Online) 2:650-658. DOI: 10.18632/aging. 100200

Ma D, Yu Y, Yu X, Zhang M, Yang Y (2014) The changes of leukocyte telomere length and telomerase activity after sitagliptin intervention in newly diagnosed type 2 diabetes. Diabetes Metabolism Research and Reviews 31: 256-261. DOI: 10.1002/dmrr.2578

Parks JW, Stone MD (2017) Single -molecule studies of telomeres and telomerase. Annual Review of Biophysics 46: 357-377. DOI: 10.1146/annurev-biophys-062215-011256

Rentoukas E, Tsarouhas K, Kaplanis I, Korou E, Nikolaou M, Marathonitis G (2012) Connection between telomerase activity in PBMC and markers of inflammation and endothelial dysfunction in patients with metabolic syndrome. PLoS ONE 7: e35739. DOI: 10.1371/journal.pone.0035739

Salpea KD, Humphries SE (2010) Telomere length in atherosclerosis and diabetes. Atherosclerosis 209: 35-38. DOI: 10.1016/j.atherosclerosis.2009.12.021
Serra V, Grune T, Sitte N, Saretzki G, von Zglinicki T (2000) Telomere length as a marker of oxidative stress in primary human fibroblast cultures. Annals of the New York Academy of Sciences 908:327-330. DOI: 10.1111/j.17496632.2000.tb06666.x

Shay JW (2016) Role of telomeres and telomerase in aging and cancer. Cancer Discovery 6:584-593. DOI: 10.1158/21598290.CD-16-0062

Skvortsov DA, Zvereva ME, Shpanchenko OV, Dontsova OA (2011) Assays for detection of telomerase activity. ACTA Nature 3: 48-68.

Sun X, Han F, Yi J, Hou N, Cao Z (2013) The effect of telomerase activity on vascular smooth muscle cell proliferation in type 2 diabetes in vivo and in vitro. Molecular Medicine Reports 7: 1636-1640. DOI: 10.3892/mmr.2013.1350

Tamura Y, Takubo K, Aida J, Araki A, Ito H (2016) Telomere attrition and diabetes mellitus. Geriatrics \& Gerontology International 16: 66-74. DOI: 10.1111/ggi.12738

Tntolouris N, Nzietchueng R, Cattan V (2007) White blood cells telomere length is shorter in males with type 2 diabetes and microalbuminuria. Diabetes Care 30:2909-2915. DOI: $10.2337 / \mathrm{dc} 07-0633$

Verzola D, Gandolfo MT, Gaetani G (2008) Accelerated senescence in the kidneys of patients with type 2 diabetic nephropathy. American Journal of Physiology 295:F15631573. DOI: 10.1152 /ajprenal.90302.2008

Wei L, Wu M, Yan Z, Shen F, Xie T, Qian Q, Cui Z, Shi J, Guo Y (1997) Detection of human telomerase activity by telomerase TRAP-ELISA assay. Chinese Journal of Cancer Research 9: 277-280. DOI: 10.1007/BF02974974

Yao DF, Wu W, Yao M, Qiu LW, Wu XH, Su XQ, Zou L, Yao DB, Meng XY (2006) Dynamic alteration of telomerase expression and its diagnostic significance in liver or peripheral blood for hepatocellular carcinoma. World Journal of Gastroenterology $\quad 12: \quad 4966-4972 . \quad$ DOI: 10.3748/wjg.v12.i31.4966

Zhao J, Zhu Y, Lin J, Matsuguchi T, Blackburn E, Zhang Y, Cole SA, Best LG, Lee ET, Howard BV (2014) Short leukocyte telomere length predicts risk of diabetes in American Indians: the strong heart family study. Diabetes 63: 354-362. DOI: $10.2337 / \mathrm{db} 13-0744$ 